terminology appertaining to each subject should be a responsibility of the international scientific or technicul organization cultivating that subject. The first step should be to distinguish and to register under serial numbers the actual concepts, regardless of what words may rightly or wrongly be associated with those concepts according to the usages of different languages. In each language certain expressions should be standardized in the sense of being officially recommended for denoting particular concepts, as distinguished by sketches if concrete or by verbal definitions if abstract. Dr. Holmstrom visualizes the international organization desiring a dictionary for its special subject as first adopting a list of the requisite terms, together with illustrative sketches or definitions or descriptive verbal contexts in any suitable basic language and numbering them for reference. The agreed and numbered definitions, but not the terms themselves, would then be translated into each of the other languages desired and would be sent to authoritative organizations in countries using those languages. These organizations would respond with lists of the terms in their respective languages which they recommended should be associated with the numbered definitions or illustrations, and the international organization would then publish a dictionary quoting the terms thus collected, with or without the definitions or illustretions.

Dr. Holmstrom also directs attention to the advantage gained if no term intended for inclusion in a dictionary need be copied more than once from the time it is first suggested to the time it appears in the published work.

The bibliography which accompanied the original report has now been published separately*. It now includes 1,044 references grouped under 224 subject heads in accordance with the Universal Decimal Classification numbers, and taken from forty-five languages. The bibliography is bilingual, in French and English, and is provided with a language index as well as with the customary author and subject indexes. Fifty further dictionaries are listed in a supplement.

* Bibliography of Interlingual Scientific and Technical Dictionaries. By Dr. J. F. Holmstrom. Serond edition, with corrections and supplement. Pp. 232. (Paris: Unesco; London: H.M. Stationery Office,

\section{CONTEMPORARY PSYCHOLOGY IN THE SOVIET UNION}

PAPER by Ivan D. London, of Harvard
University, on "Contemporary Psychology in
the Soviet Union"*, discusses the present-day general
policy towards the subject which the Soviet Govern-
ment is forcing its psychologists to adopt ; the
paper cites 104 references with full titles and dates
of publication. It appears that the genetics con-
troversy of 1948 in the U.S.S.R. was followed in
1950 by a similar controversy ; but this time concerned
with physiology and the allied subject of psychology,
the alleged focal point being the work of Pavlov.
Apparently, writers in the U.S.S.R. concerned with
these two sciences have not shown sufficiently strong
allegiance to the "materialistic foundations" of
Pavlov. Although in the prefaces to their books
Soviet physiologists and psychologists referred to the
"materialistic foundations bequeathed to them by
Pavlov", they proceeded to develop their sciences without much reference to his theories. Trouble resulted, and Rubinshtein, the only Soviet psychologist to date to develop a respectable general psychology on paper, had to confess to a "grievous sin" in that in his book of 685 pages, "Bases of General Psychology", he takes up questions connected with Pavlovian theory on only six pages. The American and English physiologists, Liddell and Sherrington, have been accused of showing evidence of "a bourgeois plot", and Sherrington and Pavlov personify respectively the forces of evil and good. Pavlov, who died in 1936, is represented as always an upholder of present-day Soviet theses and as being a posthumous supporter of Lysenko.

The consequence is that psychology in the U.S.S.R. has become an uninspiring discipline, more a matter of programme than of accomplishment, and even the work of out-and-out Pavlovians is little more than an unimaginative rehashing of past experiments. Some interesting experiments of Anokhim and his co-workers led to an attempt to escape from the limitations of the standard Pavlov technique, and he devised a general method which he calls the "method of active choice". In his view the role of reflexes as such is subordinated to that of "large-scale functional systems" (1949). He has, however, been condemned for his deviationism from the Pavlov theory. •

In the field of sensation and perception, particularly that concerned with "sensory interaction", there is considerable Soviet work of apparent competence. Any non-visual stimulation that increases retinal sensitivity to green light has been found to decrease it to red light. Substances which heighten sympathetic excitability, such as adrenalin and ephedrine, increase retinal sensitivity to light in the green-blue region of the spectrum. Substances which heighten parasympathetic excitability, such as pilocarpine, increase sensitivity to light in the orange-red region (1950). Other interesting investigations are concerned with brain-function in its normal, pathological and restorative aspects.

Since 1936, educational psychology in the U.S.S.R. has been relegated in the main to the service of pedagogy. On the basis of an observational study of three gifted children, a psychologist notes that talent is accompanied by a remarkable inclination to work. The conclusion is drawn that "workers have an enormous advantage over the parasitic classes, and that in spite of the test-data of foreign scientists there is greater talent in the working classes"

There are a number of Soviet psychological journals ; but the quality of the papers is extremely uneven, and the intrusion of political propaganda is a common feature. When in 1947 a second edition of Rubinshtein's "Bases of General Psychology" was published, although in 1942 it had been awarded the Stalin Prize, he was unreasonably attacked because it was said that he had neglected the psychology of the "new Soviet man", and had not correctly resolved the psycho-physical problem. The political and ideological strait-jacketing of psychology in the U.S.S.R. has been both restrictive and deleterious to its development; in contrast to the treatment of psychology, some branches of mathematics and of the physical sciences rival comparable work in other countries.

* Contemporary Psychology in the Soviet Union. By Ivan D. Massachusetts.) From Science, 114, 227-233 (1951). 